\title{
Etnografia e fluxo transnacional: congoleses em seus trânsitos
}

Mariana Batista dos Santos ${ }^{1}$ Universidade Federal Fluminense

Resumo: O artigo busca, a partir de dois contextos etnográficos, refletir sobre questões envolvendo fluxos transnacionais de congoleses dentro e fora do Brasil, abordando as macropolíticas com que se relacionam e a produção de conhecimentos em meio a estes fluxos.

Palavras-chaves: fluxo transnacional, estudantes, sapeurs, etnografia, Congo. 


\title{
Ethnography and transnational flow: Congolese in their flows
}

\begin{abstract}
From two ethnographic contexts, the article seeks to reflect issues involving transnational flows of Congolese inside and outside Brazil, addressing the macropolitics with which they relate and the production of knowledge in the midst of these flows.
\end{abstract}

Keywords: transnational flow, students, sapeurs, ethnography, Congo.

\section{Etnografía y flujo transnacional: congoleños en su trânsito}

Resumen: Desde dos contextos etnográficos, el artículo busca reflejar cuestiones relacionadas con los flujos transnacionales de congoleños dentro y fuera de Brasil, abordando la macropolítica con la que se relacionan y la producción de conocimiento en medio de estos flujos.

Palabras clave: flujo transnacional; estudiantes; sapeurs; etnografía; Congo. 


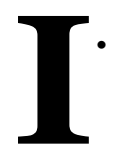

Em minha pós-graduação, realizada na Universidade Federal Fluminense, realizei duas pesquisas que abordam o tema dos fluxos transnacionais e de como os sujeitos elaboram seus projetos em meio a estes fluxos. Nas duas pesquisas, tive a alegria de ter sido orientada pela Professora Simoni Lahud Guedes e poder conviver com o brilhantismo, a excelência acadêmica, o pioneirismo e a enorme generosidade que foram características tão marcantes de Simoni e que sempre provocaram minha admiração, assim como a de todos que tiveram o privilégio de seu convívio. Tenho muito a agradecer. Este artigo, que surgiu de uma sugestão de Simoni, é dedicado a ela.

Na primeira pesquisa, realizada entre 2011 e 2012, trabalhei com estudantes da República Democrática do Congo (RDC) que cursavam a graduação em universidades públicas do Rio de Janeiro, por meio do Programa de Estudantes-Convênio de Graduação (PEC-G). Eram jovens entre 21 e 28 anos; naturais de Kinshasa; que se concentravam principalmente nas áreas de engenharias, ciências sociais aplicadas e ciências agrárias e biológicas da UERJ (Universidade Estadual do Rio de Janeiro), UFRJ (Universidade Federal do Rio de Janeiro) e UFF (Universidade Federal Fluminense). Comecei o campo na própria UFF, onde estudava, e, na medida em que criava uma rede de relações, o campo foi se expandindo para as demais universidades. Interessava-me saber o que impulsionava os estudantes rumo a esta estadia para fins de estudo no Brasil, as trajetórias que eles vivenciavam aqui e suas expectativas para o futuro, que podiam ser voltar a $\mathrm{RDC}$, permanecer aqui ou partir para um terceiro país.

O interesse pelo fluxo de pessoas se manteve na segunda pesquisa, desta vez somado a questões de consumo e performance. Este segundo estudo, realizado na Universidade Federal Fluminense, contou com o auxílio do CNPq e apoio institucional da École des Hautes Études en Sciences Sociales, Paris, em um sanduíche que permitiu a realização do trabalho de campo, entre maio de 2014 e junho de 2015, com os sapeurs residentes na capital francesa. Os sapeurs são homens congoleses que encaram a busca pela elegância como um estilo de vida e se consideram membros da SAPE, uma sigla para Société des Ambianceurs et des Persones Élégantes - na tradução, "Sociedade dos Ambientadores e das Pessoas Elegantes”. São, portanto, dândis africanos contemporâneos, como irei elaborar mais à frente. Uma vez que a própria dinâmica da SAPE estimula o fluxo entre a República do Congo, a República Democrática do Congo e a França, eles são também imigrantes. Assim, no primeiro caso, o deslocamento se deu por parte do objeto de estudo; já no segundo caso, o deslocamento é da pesquisadora.

Partindo destes dois casos de campo, busco refletir sobre as implicações de ser uma pesquisadora brasileira na entrada e na construção de um trabalho de campo no exterior, assim como sobre a produção de conhecimentos que se dá em meio ao fluxo transnacional. Proponho pensar como as macropolíticas se refletem nas dinâmicas de campo, nos fluxos transnacionais de pessoas e em relação ao contexto político internacional da época em que as etnografias foram realizadas. Buscarei refletir estas questões tanto nas relações Congo-Brasil quanto nas relações Congo-França. 
Como afirmei, procurei refletir sobre a experiência dos universitários congoleses enquanto projetos (VELHO, 1994) que eram configurados e reconfigurados na experiência do intercâmbio. Interessava-me os planos que os motivaram a vir estudar no Brasil, como a estadia aqui redesenhava estes planos e aquilo que esperavam obter ao fim deste empreendimento, visando compreender o significado desse período de estudos na vida destes jovens em trânsito.

Estes projetos eram elaborados tanto na RDC quanto durante a vivência no Brasil e podem ser considerados como uma estratégia individual e familiar de ascensão social e econômica, uma vez que demandavam a mobilização de uma série de recursos de suas famílias neste sentido, mesmo porque, diferente dos estudantes PEC-PG (Programa Estudante-Convênio de Pós-Graduação), os PEC-G não recebem uma bolsa que possa custeá-los durante o período de estudos.

Embora muito bem planejados, estes não eram projetos "fechados", mas deliberadamente deixados em aberto, de modo a serem alterados de acordo com o campo de possibilidades que encontrassem no Rio de Janeiro. Isso se tornava bastante destacado quanto à possibilidade (ou não) de retorno ao país de origem, uma decisão importante e que, geralmente, só era tomada no final do período de estudos no Brasil. Ainda que compartilhem formas de adaptação e de negociação ao país de acolhida com outros tipos de fluxos transnacionais de pessoas, o intercâmbio pressupõe o retorno e coloca, desde o início, um prazo já pré-determinado para voltarem ao Congo. Mas, assim como há formas do programa forçar o retorno (como, por exemplo, que o diploma só seja entregue no país de origem), há também formas de permanecer (como, no caso de alguns estudantes pesquisados, estendendo a estadia como estudante de pós-graduação, tendo um filho brasileiro ou voltando a RDC para retornar ao Brasil logo em seguida). Há, ainda, a opção de partir para um terceiro país como trabalhador qualificado. Essas possibilidades eram analisadas de acordo com as oportunidades que surgissem no Brasil durante este período e com o contexto que eles consideravam lhes aguardar na $\mathrm{RDC}$. Tendo isso em vista, estruturei o trabalho de campo com base no convívio com os estudantes e em um conjunto de entrevistas realizadas de maneira individual com parte dos universitários com que mantive contato.

A escolha da metodologia adotada se deve à própria questão dos projetos e trajetórias de vida que me propus abordar. Os projetos possuem uma dimensão espaço-temporal específica que, em termos gerais, pode ser dividida em três principais momentos. No primeiro, quando ainda em Kinshasa, os estudantes ponderavam a possibilidade de estudar no Brasil, se inscreviam no PEC-G e se proviam dos recursos para tal. O segundo engloba o tempo de estudos na universidade brasileira, com todos os imponderáveis que podem ocorrer neste período; já o terceiro se refere aos rumos que os estudantes decidem seguir após formados.

Uma vez que todo o trabalho de campo foi realizado no Rio de Janeiro, mesmo tendo ciência de que a experiência de ser um universitário congolês no Brasil começa antes da chegada ao país, eu não poderia ter acesso direto a esta primeira etapa da vivência dos universitários. Tendo isso em vista, as entrevistas entraram em cena como parte da metodologia escolhida, buscando acessar a temporalidade em que estes projetos se inscrevem e compreender como os estudantes estruturavam suas trajetórias de vida por meio de narrativas.

Para Sayad (1998), "imigração" e "emigração" são perspectivas de uma mesma e única vivência, embora a sociedade de acolhida as enxergue como dois 
movimentos distintos, criando uma fissura na experiência do então "imigrante", que a permite ignorar toda experiência anterior do sujeito em seu país de origem. Tendo isto em vista, as entrevistas se apresentavam como forma de recuperar esta história pregressa para o leitor brasileiro.

Entretanto, isto trouxe também o questionamento sobre até que ponto o estudante pode ou não ser considerado um imigrante, mesmo porque, para este autor, "migrante" dificilmente poderia ser compreendido como uma categoria nativa, mas uma classificação imposta pela sociedade na qual este "migrante" busca se inserir e que só faria sentido para esta. Hage (2005), por sua vez, argumenta que o status seria o principal fator a classificar certos grupos como sendo imigrantes ou não: trabalhadores exercendo profissões menos remuneradas são considerados imigrantes, banqueiros não o são. Este é um debate que vem sendo realizado por pesquisadores que se dedicaram ao tema dos intercâmbios estudantis $^{2}$. E, efetivamente, os universitários não utilizam a categoria de "imigrante" para se referir a si mesmos, mas se distinguem do que geralmente chamam de "os outros congoleses no Brasil" por se perceberem como tendo uma forma especifica, própria da condição de estudante, de vivenciar a mobilidade. Além do que, embora sejam estudantes de nível superior e pertençam às camadas médias e médias altas de seu país, eles são africanos negros e precisam lidar com os desafios e estereótipos aos quais os africanos e o povo preto em geral são submetidos no Brasil. Assim, se afirmar enquanto estudante e recusar a classificação como imigrante pode ser, também, acionado como uma defesa frente a situações de preconceito, tal como explorado por Hirsch (2007) e Subuhana (2005). Tendo isto em vista, optei pelos termos "fluxo" e "trânsito", mais do que "migração", por considerar os dois primeiros mais flexíveis, como flexível é a estadia dos universitários aqui: um tempo que lhes abre um leque de possibilidades, mas, ao mesmo tempo, as mantêm ainda em suspenso.

Há ainda outra proposta de Hage que gostaria de explorar, que é a de imigração enquanto uma categoria tão objetiva quanto subjetiva. Um dos raros momentos em que presenciei um ex-estudante - que atualmente se encontra formado, trabalhando e constituiu família aqui - se referir a si mesmo como imigrante foi ao afirmar que "eu acabei migrando para o Brasil", não para se referir à opção em vir estudar aqui, mas para comunicar a decisão, tomada já após alguns anos vivendo no Rio de Janeiro, de construir sua vida no país. Migrar, neste caso, não era partir para outro lugar, mas a decisão ponderada de permanecer onde se está. A mudança não é física, mas de perspectiva, trazendo elementos ao tema do fluxo de pessoas que ultrapassam a questão da temporalidade e da mobilidade espacial e que se tornam significativos quando consideramos a subjetividade envolvida neste processo.

Daí a opção por trabalhar com narrativas de vida, por meio das quais os universitários construíam suas interpretações sobre este passado em Kinshasa, o presente no Rio e as aspirações para o futuro, articulando estas espacialidades distintas em que eles coabitam simultaneamente, a subjetividade envolvida e a temporalidade específica a este trânsito.

Cabe, ainda, atentar que a entrevista não é uma representação direta da vida do informante, mas uma interpretação produzida para a situação de entrevista e que, mesmo quando versa sobre o passado, é sempre construída a partir do presente. Deste modo, o narrado é mediado e ganha uma coerência, linearidade e um

${ }_{2}$ Mungoi (2006) e Subuhana (2005) classificam este fluxo como "migração temporária”, Hirsch (2005) traz a possibilidade de que os estudantes sejam "migrantes potenciais" ou "migrantes virtuais", enquanto que Morais (2012) se opõe radicalmente à classificação dos estudantes-convênio enquanto "migrantes". 
senso de propósito que não equivale à descontinuidade e imprevisibilidade do vivido, mas que permite a produção de significados a partir do ponto de vista dos próprios entrevistados. Retornarei a este tema mais à frente, ao tratar do trabalho de campo com os sapeurs.

Recorri também ao convívio e à observação como ferramentas para compreender como as interações se davam e como as trajetórias se desenhavam a partir da matéria do dia a dia. Meu foco recaiu sobre as atividades sociais, já que seria bastante complicado assistir aulas junto aos estudantes. Acompanhei reuniões em repúblicas, em praças ou bares próximos às universidades, assim como passeios e jogos de futebol e basquete.

Fiquei um pouco mais próxima dos estudantes que estavam há menos tempo no Brasil pois eu acabava sendo uma pessoa com quem se poderia praticar português para a prova Celpe-Bras 3 , em um momento no qual eles ainda não tinham tantas relações com outros brasileiros, ou alguém com quem tirar dúvidas sobre o país (eles me perguntavam desde questões sobre a política brasileira até por quê os cariocas, quando se sentam no chão, cruzam as pernas), obter dicas ou apresentar lugares no Rio de Janeiro. Como ocorre com os estudantes congoleses que estão há mais tempo no país, eu me esforçava em preencher este papel de mediadora para os mais recentemente chegados, com a diferença de ser uma insider na cidade. E foi durante um passeio com os universitários para conhecer pontos turísticos do Rio, que entramos casualmente em um centro cultural onde estava acontecendo uma exposição do fotógrafo congolês Baudouin Mouanda, em que este retratava a SAPE da República do Congo, o que se revelou uma grata surpresa para nós e me apresentou ao objeto da pesquisa seguinte.

Considero que o PEC-G e o PEC-PG proporcionam uma circulação e uma produção de conhecimentos em via de mão dupla. Há um fluxo de conhecimentos que se move do Brasil em direção aos países participantes do convênio, assim como há outro fluxo de conhecimentos vindos desses países em direção ao Brasil. É uma produção de conhecimento que é realizada na universidade brasileira e que carrega as características particulares do próprio trânsito que viabilizou esta produção de saberes.

Ao ler algumas das teses, dissertações e artigos escritos por estudantes PECG e, principalmente, PEC-PG, percebi um certo "olhar de estrangeiro", que seria esta capacidade de perceber coisas que muitas vezes escapam aos locais, próprio da sua condição e que também caracteriza a antropologia como disciplina que se construiu através da reflexão sobre a alteridade. Outra característica é que estes autores combinam bibliografia brasileira com autores que trazem de seus países - o que, uma vez que são textos produzidos no Brasil e que circulam na academia brasileira, acaba por ampliar também a gama de referências bibliográficas dos próprios pesquisadores brasileiros, assim como levam bibliografia brasileira para seus países de origem. Os dois programas produzem conhecimentos que, assim como os estudantes, transitam pelos dois lados do Atlântico e carregam características do próprio fluxo que possibilitou sua produção. Pois os universitários do PEC-G / PEC-PG têm de estar todo o tempo negociando formas de se viver em uma cultura distinta e, ao realizarem esta negociação com a alteridade, refletem sobre a mesma. Não é de surpreender, então, que parte da bibliografia disponível sobre estudantes-convênio no Brasil tenha sido realizada por pesquisadores que também viveram a experiência de realizar parte de sua formação no Brasil. ${ }^{4}$ Além

3 Certificado de Proficiência em Língua Portuguesa para Estrangeiros, um exame iniciado pouco antes

dos estudantes começarem o curso universitário propriamente dito.

${ }_{4}$ Como os estudos de Mungoi (2006), de Subuhana (2005) e Kaly (2001). Outro exemplo, ainda que não tenha se dedicado especificamente ao tema dos estudantes-convênio, é Kabenguele Munanga (2004), que também realizou parte da pós- 
do que, há um número muito grande de pesquisadores que passaram pela experiência de serem estudantes-convênio escrevendo sobre as mais variadas áreas e temáticas como, por exemplo, pesquisas em direito, arquitetura, biologia etc. Esta produção realizada por estrangeiros inseridos na universidade brasileira e tendo pesquisadores brasileiros como interlocutores é, portanto, muito extensa.

A origem do PEC-G data da década de 1920, quando estudantes da América hispânica chegavam às universidades brasileiras, seja por iniciativas individuais quanto por meio de convênios esporádicos com outros países latino-americanos. Esses convênios passaram a ser sistematizados e denominados como PEC-G em 1964, com a proposta de estimular a vinda destes estrangeiros. O PEC-G, assim como outros convênios anteriores, eram administrados exclusivamente pelo Itamaraty e é apenas em 1967 que o PEC-G passa a ser coordenado por dois ministérios em conjunto: o Ministério das Relações Exteriores (MRE) ou Itamaraty e o Ministério da Educação (MEC).

O PEC-G e PEC-PG são, também, relações diplomáticas, de modo que uma das questões sobre a qual busquei refletir foi como as relações exteriores e o contexto político que lhe acompanha se articulam ao trabalho de campo e à produção de conhecimento que o envolve. Assim, fui buscar o que a área de relações internacionais tinha a me dizer a respeito das relações recentes entre Brasil e a África Subsaariana.

As relações internacionais entre Brasil e o continente africano se intensificam na década de 1960, quando muitos países africanos se tornam independentes. Até então, a maior parte das relações políticas e econômicas entre Brasil e o continente africano eram mediadas pelas metrópoles e não havia diálogo direto entre Estados africanos e o Estado brasileiro - transações entre Moçambique e Brasil, por exemplo, geralmente passavam por Lisboa.

Quanto aos acordos envolvendo especificamente o fluxo de estudantes, é em 1960 que chega ao Brasil o primeiro grupo de universitários africanos, composto por 16 jovens de Cabo Verde, Senegal, Gana e Camarões, que inauguram os intercâmbios estudantis entre Brasil e África (MUNGOI, 2006: 28). Eles chegaram via um convênio distinto do PEC-G, uma vez que este só passa a incorporar estudantes que não sejam latino-americanos em 1974. Atualmente, 47 países participam do PEC-G, sendo 25 países africanos.

Retornando às relações diplomáticas para além dos convênios-estudantis, as trocas entre Brasil e África se intensificaram na década de 1970, ainda que a diplomacia durante a ditadura militar tenha se focado apenas em alguns parceiros privilegiados e não diversificado as parcerias com os Estados africanos. As relações entre Brasil e África sofreram um desvanecimento nos anos 1990 e não receberam destaque no período FHC. Já nos dois mandatos do ex-presidente Lula, estas foram consideravelmente ampliadas, impulso que se manteve, ao menos, até o período em que esta pesquisa foi realizada, no primeiro mandato da presidenta Dilma Rousseff (VISENTINI, 2015; SARAIVA, 2004).

Foram firmados 271 atos de cooperação, embaixadas brasileiras foram inauguradas e visitas mútuas foram ampliadas. Especificamente sobre as relações entre RDC e Brasil, o saldo da balança comercial entre os dois países teve um crescimento de $2.573,63 \%$ entre 2003 e 2007 (LECHINI, 2008), o que demonstra um direcionamento da política externa, pois este salto só é possível em comparação

graduação no Brasil e reflete sobre ser negro no país. E, ainda que não lide diretamente com a proposta do artigo, vale lembrar o papel dos estudantes africanos no exterior na difusão do movimento pan-africanista, no processo de descolonização, na construção dos Estados e produção acadêmica de suas pátrias (APPIAH, 1997). 
ao saldo comercial ínfimo anterior, indicando menos um crescimento comercial propriamente dito e mais uma determinada direção de política de Estado.

O discurso brasileiro sobre a cooperação Sul-Sul - entendendo-se por cooperação Sul-Sul uma agenda comum aos países fora do hemisfério norte, especialmente os da América do Sul, África e Ásia - foi construído, sobretudo, pelos diplomatas. Afirma-se as relações do eixo sul-sul como mais horizontais e solidárias, respeitando os princípios de não impor condições e não interferir nas questões domésticas de cada país, em contraposição à cooperação tradicional NorteSul, tida como mais vertical e intervencionista. O Brasil é apresentado como tendo enfrentado problemas mais próximos aos dos demais países do Sul e obtido relativo sucesso nesta empreitada; de modo que, pela própria experiência prévia e periférica como receptor de ajuda, teria como oferecer soluções melhores que as do Norte. Entretanto, embora procure demarcar um espaço próprio ao se distinguir da cooperação tradicional, é fato que a cooperação Sul-Sul emerge não como um modelo alternativo, mas dentro de uma hegemonia já existente, com a qual se relaciona. O que inclui questões de soberania e também a busca do reconhecimento do Norte como um de seus pares, como indica a aspiração por uma cadeira permanente no Conselho de Segurança da ONU. De modo que, a cooperação Sul-Sul brasileira se apresentaria menos como "um aparato estável, coerente e efetivamente alternativo e sim uma composição de relações emergentes entre atores e processos preexistentes, incluindo o hemisfério norte" (CESARINO, 2014: 29).

Através da experiência de campo, pude perceber que, apesar da imagem positiva que o país gozava no exterior, a vivência no Rio de Janeiro produzia um descompasso entre o cotidiano vivido aqui e a forma como o país era representado nas relações internacionais, dentre elas o próprio programa PEC-G, e nos meios de comunicação. Este descompasso ecoa com o exposto por Cesarino (2012), de que a cooperação Sul-Sul não formaria uma definição unificada e coerente para seus próprios agentes, mas que seria muito mais plural. Para alguns, a cooperação Sul-Sul seria um modelo efetivamente alternativo. Para outros, ela se pautaria nas relações tradicionais, pois reproduziria o mesmo modelo destas últimas em menor escala. Há, ainda, os que veem como complementar, embora autônoma, à cooperação Norte-Sul. As diferenças se fazem presentes, também, entre o nível diplomático e o operacional, dos pesquisadores e técnicos brasileiros em diálogo com instituições de pesquisa africanas. A diplomacia, no período em que as duas pesquisas foram realizadas, adotava um discurso mais culturalista, que ressaltava as afinidades e os laços históricos entre Brasil e o continente africano enquanto elementos agregadores e que refletia ainda nosso próprio processo de nation building, com seus avanços e retrocessos na integração plena dos afrodescendentes. Afirmava-se, ainda, que o Brasil teria experiências, tecnologias, conhecimentos, clima e desafios mais aproximados ao dos demais países do Sul, o que favoreceria a criação de pontes e de propostas a serem compartilhadas. Mas este contexto construído pelos diplomatas encontrava pouca ressonância no nível operacional, que via questões práticas de pesquisa e de mediação com a cooperação tradicional Norte-Sul como muito mais relevantes (CESARINO, 2012).

Se as relações diplomáticas entre Brasil e África buscavam positivar a cooperação e valorização da herança africana no Brasil, isso não se concretizava na proporção que os universitários aguardavam. Ao contrário, eles se espantavam com o desconhecimento de grande parte dos brasileiros sobre a África e a RDC, assim como com as representações que, a despeito da enorme diversidade do continente 
africano, circulam em meio à população brasileira e em nossos meios de comunicação. Tampouco encontraram a "democracia racial" que se costuma apregoar. ${ }^{5}$ Apesar de perceberem o quanto de África está presente no Brasil, por vezes vivenciavam situações de franco preconceito, tanto em relação à "africanidade" quanto à "negritude". Tal experiência pode ser tão agressiva a ponto de fazer com que estudantes que pretendiam seguir vivendo no Brasil mudem de ideia e decidam voltar a RDC ou, ainda, em fixar residência em um terceiro país. Some-se a isso a falta de estrutura das universidades brasileiras para recebê-los. Em resumo, o Brasil não cumpria com as expectativas que gerava.

Por outro lado, o argumento diplomático de que o Brasil e a RDC, devido à própria situação periférica (ainda que se trate de periferias bastante distintas), teriam desafios e conhecimentos mais aproximados encontrava alguma ressonância entre parte dos estudantes. Se o ensino superior no Brasil não é, costumeiramente, a primeira opção dos universitários PEC-G; ele poderia, no entanto, ser considerado um conhecimento mais próximo ao contexto da RDC do que o obtido nos países com que eles sonhavam como primeira opção para realizarem seus estudos.

Em "O campo na selva visto da praia", Viveiros de Castro (1992) revê sua trajetória e problematiza as questões que o levaram a pesquisar etnologia no Xingu. Viveiros de Castro pontua que, no momento em que começou sua carreira, era pouco viável a um antropólogo brasileiro conseguir recursos para realizar pesquisa fora das fronteiras nacionais, de modo que a opção por se tornar americanista se relacionaria tanto com fatores subjetivos (vontade de "fugir do Brasil", tédio com a sociologia do desenvolvimento...) quanto com o contexto da antropologia nacional da época, que também se insere em um contexto político brasileiro mais amplo.

\begin{abstract}
Se estudei índios no Brasil, é porque a antropologia praticada por aqui se concentra quase exclusivamente em fenômenos intramuros. Não porque buscasse, contudo, qualquer conexão entre os índios do Xingu e a "realidade brasileira" - tornei-me americanista e não brasilianista. Mas se me tornei americanista, e não africanista ou oceanista, foi porque fazer etnologia no Brasil significava estudar índios no Brasil, país periférico sem (ex-)colônias externas. Meus professores eram americanistas; e finalmente, não teria sido fácil obter financiamento do CNPq, da FINEP ou do escritório brasileiro da Fundação Ford para fazer pesquisa na Nova Guiné. Em outras palavras, ser um americanista brasileiro não é de forma alguma a mesma coisa que ser um americanista francês ou inglês. (VIVEIROS DE CASTRO, 1992: 4)
\end{abstract}

Diferente do descrito por Viveiros de Castro, considero que tanto os projetos dos estudantes em buscarem a universidade brasileira quanto meu próprio projeto de pesquisa refletiam um período em que se dispunha de mais facilidade em realizar estudos para além das fronteiras nacionais e no qual o Estado brasileiro buscava ampliar sua influência nas relações diplomáticas, especialmente com outros países do sul e mesmo com seus contratempos trouxe a abertura real de todo um campo de possibilidades, afetando a forma como pesquisadores direcionam suas carreiras.

A RDC conta com uma rede universitária que pode ser considerada relativamente extensa, o que torna claro que estudar fora do país é uma opção. A experiência estrangeira não é fruto de uma carência, mas de uma escolha. Eles consideram que o mercado de trabalho congolês ainda não se recuperou dos conflitos que ocorreram no país e que os estudos realizados no exterior possibilitariam uma maior empregabilidade e mais chances de ocuparem cargos melhor remunerados, seja na RDC ou fora dela, uma vez que consideram que o diploma congolês não

5 Para mais informações a respeito das representações sobre o Brasil que circulam no continente africano e o contraste entre estas e o que os estudantes de fato encontram ao chegarem aqui, ver Kaly (2001). 
seria tão bem-aceito no Brasil. A correspondência cada vez menor entre ensino universitário e posição social na RDC estimula a busca pelo diploma estrangeiro, de modo a retornarem a este cenário competitivo com este diferencial. Esta ambição se reflete também na escolha do curso estudado, geralmente escolhido por oferecer um mercado de trabalho mais seguro e/ou mais bem remunerado.

A expectativa de que o diploma obtido no estrangeiro seja financeiramente recompensado na volta para casa é nutrida por boa parte dos estudantes-convênio. No entanto, ela não é unânime, já que há estudantes que não fazem planos de retornar a RDC após concluírem a universidade, em parte por não estarem seguros a respeito desta recompensa, preferindo fixar residência aqui definitivamente. E, assim como são atribuídos status distintos aos diplomas obtidos dentro e fora do país, em diálogo com o tema das periferias e centralidades, eles também fazem gradações entre o ensino superior dos diversos países estrangeiros. A maior parte dos universitários tinha como primeira opção o intercâmbio em países (como Estados Unidos, França, Inglaterra e Bélgica) que pudessem lhes conferir um diploma tido como de maior valor simbólico a ser posteriormente convertido em vantagens econômicas e profissionais e vieram ao Brasil como segunda opção.

Abordarei agora a já citada etnografia realizada com os sapeurs; focando no trabalho de campo e nas implicações de ser uma brasileira fazendo trabalho de campo com dândis congoleses na França. Mas, antes, cabe expor, ainda que brevemente, quem são os sapeurs e o quê é a SAPE. Trata-se de homens congoleses, tanto da República Democrática do Congo quanto da República do Congo, entre 20 e 60 anos e exercendo profissões tão distintas quanto comerciante, médico, motorista, mestre de obras, cabeleireiro e cozinheiro. Eles formam um grupo muito plural, mas que se agrega em torno da origem em comum e do culto à elegância como um fim em si mesmo. A construção desta elegância passa pela observação de uma etiqueta própria à SAPE, pelos cuidados com a aparência e pelo consumo de grifes europeias luxuosas. Assim, a sigla SAPE remete também a um verbo: "se saper" é se vestir bem; "bien sapé", estar bem-vestido. É importante estarem sempre perfumados, barbeados, com sapatos engraxados, e é essencial ostentarem grifes de peso, tais como Yves Saint Laurent, J. M. Westorn, Versace, Salvatore Ferragmo, Yohji Yamamoto, porém vestidas à maneira muito particular dos sapeurs. Ao se apropriarem destes objetos, os sapeurs criam novos usos e significados para eles. Eles não seguem fielmente as passarelas, mas criam um estilo próprio que se caracteriza pela exuberância. Ao contrário do que o elenco de grifes pode sugerir, eles não integram uma elite econômica, mas vêm das camadas médias e populares congolesas e custeiam as roupas de luxo através de uma série de sacrifícios cotidianos, em que se economiza nas pequenas coisas para se permitir as grandes. O consumo não é apenas uma questão econômica ou de classe social, mas também de moralidades.

Embora a SAPE se apresente como uma "sociedade", ela não o é no sentido mais habitual de uma sociedade institucionalizada. Ela é uma "sociedade" enquanto categoria nativa de um grupo de pessoas que compartilha um estilo de vida na qual a elegância é uma condição de estar no mundo e se organiza de maneira mais informal - ser membro da SAPE significa se vestir, se pensar e ser reconhecido pelos demais enquanto tal. Estas roupas e acessórios são mais valo- 
rizados quando obtidos na França e, particularmente, na cidade de Paris, considerada como a capital da alta-costura. Estar em Paris significa ter acesso privilegiado a este imaginário e confere um acréscimo de prestígio aos que passam por essa experiência.

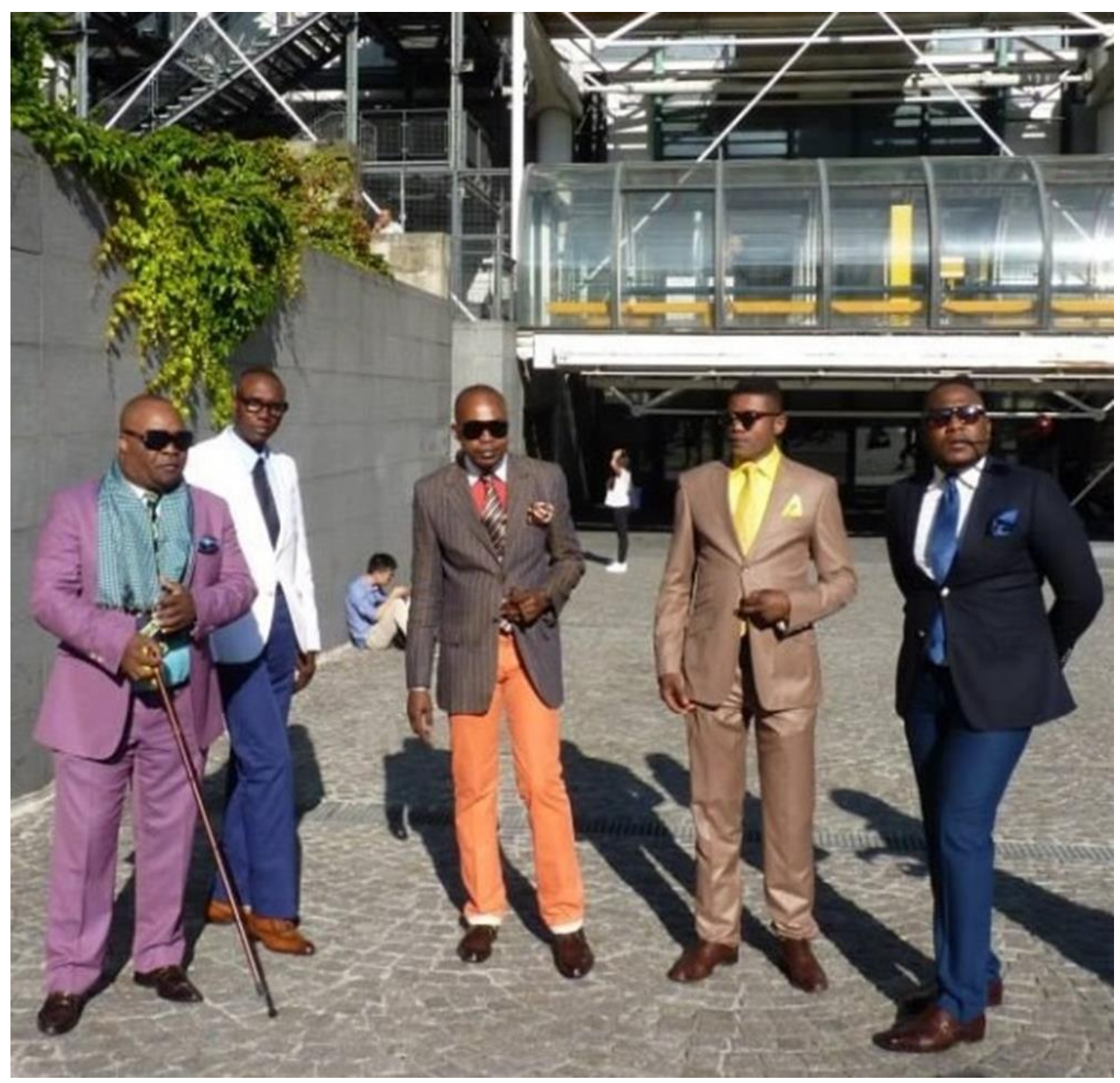

Foto 1. Da esquerda para a direita: Ben Mukasha, Majesty, Gentleman, Terminator e Yann Colère se apresentam no Marché de la Poésie, em edição deste evento dedicada a literatura congolesa, em 2014. Foto da autora.

Assim, o sapeur que vai à França e retorna à cidade natal congolesa com a mala cheia de roupas de grife passa a ser visto pelos sapeurs que vivem no Congo como um "grand" (grande), o que é um título de prestígio e faz com que a SAPE seja, também, um projeto de realização pessoal, no qual as roupas de luxo funcionam como uma espécie de troféu que comunica o sucesso da experiência transnacional do sapeur. A maior parte deles acaba se estabelecendo permanentemente na Europa, seja por gostar de viver lá ou por considerar que a economia congolesa não favorece que retornem à terra natal. Mas, sempre que possível, eles buscam realizar viagens de retorno aos Congos, o que requer uma situação financeira que permita arcar com os custos da viagem, mas significa também ter o que ostentar: é preciso inserir novidades ao guarda-roupa de grife, inclusive como forma de atualizar para o público congolês o que ele obteve em sua estadia na 
França desde sua última visita à cidade natal. A SAPE é, portanto, um tipo muito particular de fluxo de pessoas e coisas, que não acontece exatamente nem na França e nem nos Congos, mas no fluxo entre eles.

Os sapeurs aderem, simultaneamente, a dois imaginários distintos. Um, eurocentrista, que afirma a expertise francesa na produção de roupas de luxo e impulsiona o fluxo para este país. Outro, que subverte este mesmo eurocentrismo, ao afirmar serem os congoleses quem melhor domina a arte do dandismo, sabendo vestir e apreciar as roupas francesas melhor do que os próprios franceses. A "sapelogie" traz consigo este emaranhamento de estéticas, éticas, dissonâncias, agências e narrativas, por vezes conflitantes mas, sobretudo, permeáveis entre si, que é característica da própria pós-colonialidade na qual a SAPE se insere. De modo que, como salienta Pires (2017:1 67):

\begin{abstract}
Viver a pós-colonialidade não se limita a uma relação entre nações ex-colonizadas e exmetropolitanas. Os efeitos dessa época não acabam nas políticas migratórias, nas relações com a pluralidade dos dois lados do Atlântico, e nem mesmo com a economia transnacional que penetra naquilo que um dia foi chamado de periferia. A pós-colônia, como nos ensinam Mbembe, Scott, Glissant e outros, é também um espaço-tempo de produção de subjetividades e modos de vida (isto é, de produção de si mesmo e de outrem)
\end{abstract}

Aderir a dois imaginários distintos, portanto, não é exclusivo aos sapeurs. É condição da própria globalização, que interconecta o globo, e da pós-colonialidade em geral, com sua originalidade e subjetividade específica, e que embora forjada de um encontro violento que produz um poder-saber com efeitos de longa duração, não se resume a violência. E esta dupla adesão é algo que eles enfatizam em sua apresentação de si, talvez ao se utilizarem da moda como um espaço menos "sacralizado"6 e, portanto, mais propício (BOURDIEU,1983) para se colocar em questão temas que ainda seriam difíceis de expor em outros espaços tidos como mais legítimos.

Fenômeno urbano e surgido no início dos anos sessenta, logo após as independências congolesas, a SAPE é um movimento contemporâneo com raízes antigas. O antigo Reino do Kongo já possuía uma rica tradição de roupas e ornamentos que, com a colonização, vieram a conviver com as roupas europeias e os tecidos indianos que eram importados, mas com uma diferença significativa entre eles: enquanto o uso de itens que comunicavam maior status, como as joias e os elaborados tecidos de ráfia, era exclusivo à parcela da população que pertencia à aristocracia tradicional e interdito aos demais, o acesso às roupas europeias era livre a qualquer um que tivesse dinheiro para pagar por elas. Com isso, grupos emergentes, mas que não faziam parte da elite, irão prontamente aderir ao vestuário estrangeiro. Ao se introduzir e conferir valor também às roupas estrangeiras, abala-se o monopólio tradicional do adorno, que era um monopólio aristocrático (MARTIN, 1994). A ênfase nas relações mercantis provoca um movimento de migração para as grandes cidades, que experimentam um crescimento demográfico explosivo e urbanização acelerada. Amplia-se a gama de produtos oferecidos no mercado, acompanhado de um comércio paralelo de itens usados ou mais populares, permitindo a expansão deste público consumidor urbano que se formava e caracterizando a grande cidade não como local de oposição entre uma tradição local e uma modernidade exógena, mas como o espaço onde relações,

\footnotetext{
${ }^{6}$ Seguindo a proposta de Bourdieu, que realiza uma "homologia de estrutura entre o campo de produção desta categoria particular de bens de luxo que são os bens da moda, e o campo de produção desta outra categoria de bens de luxo que são os bens da cultura legítima, a poesia ou a filosofia, etc.: ‘Por que não falar disso diretamente?' Porque estes objetos legítimos estão protegidos contra o olhar científico. Falando de um assunto menos protegido, espero mostrar mais facilmente aquilo que seria recusado se eu falasse de coisas mais sagradas" (1983:157).
} 
estéticas, costumes, poderes e moralidades diferentes e, por vezes, conflitantes, coabitam e se entrelaçam.

As roupas se tornam um fator a ser mobilizado nesta reorganização das relações sociais e há uma certa "democratização" do consumo de moda pois, ao ignorar as divisões sociais preexistentes, o colonialismo acabou permitindo que determinados grupos sociais, até então privados do jogo da aparência e da ostentação, se inserissem nas novas relações de consumo e dimensão cosmética. (MARTIN, 1994). A moda passa a ocupar um papel de destaque na vida citadina e consome parte considerável dos rendimentos dos moradores dos grandes centros urbanos congoleses nas décadas de 1940 à 1960 . A roupa passa a funcionar como um marcador de urbanidade, que comunica a adesão a um estilo de vida dito "evoluído" (évolué) e em oposição aos habitantes do interior (BALANDIER, 2013). É neste contexto que surge a SAPE.

No entanto, não quero, com este olhar para as origens da SAPE, dar a entender que os sapeurs atuais estejam simplesmente reelaborando o passado. Eles estão com os pés bem fincados no presente, mas este tempo presente é, nos termos de Mbembe (2001), uma época atravessada por múltiplas durées, temporalidades e descontinuidades que se sobrepõem, se interpenetram e seguem atuando umas sobre as outras. Esta época, enquanto interlocução ou emaranhado de diversas temporalidades vividas, é também matriz de subjetividade para aqueles que a vivenciam e é expressa pelos sapeurs através da apresentação pessoal e de sua performance.

Eles se denominam "ambientadores" (“ambianceurs"); ou seja, pessoas capazes de, com a sua presença, criar uma atmosfera de sofisticação ao seu redor. A "sapelogie" exige esta "ambientação" (faire l'ambiance), que é a performance realizada em suas apresentações, seja em Brazzaville, Kinshasa ou em meio à comunidade congolesa na Europa. É a posse das roupas de luxo somada à performance específica à SAPE que produz o sapeur enquanto tal e o diferencia de um homem comum; que ainda que vestido de maneira luxuosa não possui esta mesma habilidade em criar uma atmosfera glamorosa. Esta performance inclui um gestual e um modo de falar específicos, mas escaparia às questões levantadas no artigo detalhá-los. Seja como for, eles se apresentam publicamente, exibindo a si mesmos e a suas roupas, tanto um para outro quanto para o público, em um jogo de ver e ser visto. São, ainda, convidados a "ambientarem" festas e eventos, já que a presença deles garantiria uma aura "chic" à comemoração. Mesmo que possam ser remunerados para comparecer em alguns desses eventos, isso não é suficiente para que possam arcar com os custos para manter a si mesmos, suas famílias e as roupas de luxo exclusivamente com estes rendimentos e mesmo os sapeurs mais prestigiados mantêm seus empregos paralelamente às atividades como sapeurs. A SAPE é então, constituída por trabalhadores que se reúnem, sobretudo nos fins de semana, para fazer sociabilidade em torno das roupas.

O público da SAPE, geralmente composto por pessoas de origem congolesa, se reúne para vê-los principalmente nas ruas dos bairros de Barbès-Rochechouart, Château Rouge e Goutte d' Or no $18^{\circ}$ arrondissement de Paris. Trata-se de bairros multiétnicos, fortemente marcados pela imigração africana e que concentram um comércio voltado para este público, tais como restaurantes de comida congolesa, lojas de cosméticos, de roupas e tecidos africanos, bares, mercearias com produtos alimentícios importados da África, serviços de telefonia e salões de cabeleireiro afro; formando um espaço cultural, comercial e simbólico da diáspora africana na capital francesa. Atualmente, estes bairros passam por um 
processo de gentrificação que vem gradualmente empurrando a população de origem africana que eles tradicionalmente abrigaram para os arredores da cidade. A centralidade simbólica e comercial da região, no entanto, se mantém, e é lá que os sapeurs se reúnem.

E é em meio a esta população, que compõe o público da SAPE, que os sapeurs são pessoas conhecidas e reconhecidas. As pessoas desejam saber como estarão vestidos, apreciar a performance pública que realizam, tirar fotografias com eles. Mas também os param na rua para conversar sobre os assuntos mais triviais, pedem conselhos de moda, convidam-nos para o batizado de seus filhos ou para uma cerveja no bar da esquina. Eles são os "famosos da rua da frente" (MEDIAVILLA, 2013: 20). Há qualquer coisa de liminar neste estrelato, que eu situaria em algum ponto na passagem do "homem comum", anônimo, e uma celebridade no sentido tradicional do termo. Isso se reflete na interação do público com eles, que é diferente da habitual relação de inacessibilidade que se mantém, por exemplo, com cantores e atores famosos.

Talvez se deva também a esta liminaridade que a "sapelogie" passeie com tanta facilidade em meio a outras manifestações artísticas, estando presente na cultura de massa e nos meios de comunicação congoleses. Como são pessoas que buscam a fama, os sapeurs estão continuamente procurando formas de se colocarem em evidência, como ao participarem de todo tipo de eventos ou ao produzirem vídeos e DVDs nos quais são as estrelas. Também podem ser citados em letras de canções populares e dão entrevistas a canais de televisão, rádio, jornais e revistas dos Congos. Muitos colecionam recortes de jornais e revistas congolesas com fotos e reportagens sobre eles, que exibem com orgulho.

Trabalhar com pessoas que são ou desejam ser famosas é muito diferente de trabalhar com pessoas que não são e nem querem ser celebridades. A diferença entre as duas etnografias é radical. Afinal, os universitários tinham muitos planos de carreira, mas nenhum deles incluía um estrelato e não são habituados a lidar com meios de comunicação. Já para os sapeurs, ser reconhecido é um objetivo e lidar com os meios de comunicação é algo banal. Isso cria, portanto, um estar-nomundo diferente para estes dois grupos - o que, consequentemente, exige uma forma distinta de produzir os dados também. Essa característica acabou dando contornos particulares ao campo, o que me exigiu um esforço de criatividade metodológica e me convenceu que, como afirma Peirano (1995), toda nova etnografia acaba por reinventar a própria etnografia. Busquei, então, refletir sobre formas de se trabalhar com pessoas que estão habituadas a lidar com meios de comunicação e exponho as alternativas que fui descobrindo em campo para tal.

Que os sapeurs busquem estar presentes em todo tipo de mídia, como forma de se tornarem cada vez mais reconhecidos, foi algo que me abriu muitas portas. Eles se mostraram muito receptivos e dispostos a participar da pesquisa e desejavam ser fotografados e entrevistados. Por outro lado, esta foi também minha maior dificuldade em campo, uma vez que, como eles são muito habituados a lidar com os meios de comunicação, esperavam que eu agisse da mesma forma que os profissionais desta área. Ao final, acabei adotando um convívio prolongado com os sapeurs e realizando entrevistas. Em muitos casos, realizei mais de uma entrevista com o mesmo sapeur, uma no início e outra no final do campo, obtendo dois conjuntos de informações distintos entre si. As primeiras entrevistas eram marcadas por um "discurso pronto" que eles possuem para dialogar com os meios de comunicação. Pois, tal como celebridades, eles não buscavam apenas se promover, mas tinham também uma preocupação legítima sobre como a imagem deles seria vinculada e um modelo de como essa imagem deveria ser. 
“Argumentei acima que a entrevista é” uma situação provocada pelo pesquisador, na qual o entrevistado busca, através de uma série de mediações, construir um discurso que é percebido, interpretado, selecionado e dotado de finalidade a partir do momento presente. É, ainda, um discurso que emerge e é produzido para o contexto de entrevista (BEHAR, 1995; BOURDIEU, 1997). Na maior parte dos casos, este é um evento pouco comum para os informantes, o que faz com que o discurso surja em meio a um certo improviso. Avalia-se, seleciona-se, interpreta-se, rememora-se, ordena-se, ignora-se por meio de uma improvisação que é parte da própria da situação de entrevista. Ao final, trabalha-se com o produto deste improviso - que é tanto do entrevistado quanto do entrevistador. Mas ser entrevistado não é algo incomum para os sapeurs. Isso é parte da rotina deles. Consequentemente, eu diria que eles são pessoas que improvisam pouco. Eles já tinham uma ideia bem definida daquilo que diriam, do como diriam, das frases de efeito a se ter na manga e daquilo a não ser dito também. Não quero, com isso, dar a entender que as narrativas produzidas pelos universitários fossem mais "fiéis" enquanto que as produzidas pelos sapeurs fossem menos "fidedignas", mesmo porque a busca por uma verdade última dos fatos não me parece fazer qualquer sentido em meio ao fazer antropológico. Desejo apenas apontar que as narrativas dos sapeurs costumam ser mais elaboradas, com mais camadas, o que as torna mais complexas de se interpretar.

Optei por ver essas características do objeto como uma riqueza para a pesquisa, pois me davam a oportunidade de interpretar até mesmo a ausência de improviso. E isso me era muito útil, uma vez que eu estava interessada em pensar a forma como os sapeurs produzem subjetividade e um estar no mundo particular por meio das performances da SAPE, formando o que chamei de uma pessoapara-o-espetáculo. Algo que se refletiria, inclusive, a que muitos deles optem por utilizar "nomes de SAPE" para se apresentar, que funcionam como "nomes artísticos" - tais como Terminator, Victime de la SAPE ("Vítima da SAPE"), Dada Pourret ou Bachelor ("Bacharel”). Eu tinha, então, um espaço de produção de subjetividade e uma dimensão performática a mais a explorar, além de mais um conjunto de dados com que trabalhar.

Pude, assim, acessar esse discurso pensado para a mídia, o que me informava muito sobre eles e sobre a forma como ambicionavam ser vistos e retratados. Também me informava sobre aquilo que eles não gostariam que fosse enfatizado. Não que escondessem informações sobre suas vidas: caso eu perguntasse, eles geralmente respondiam sem problemas, mas consideravam que falar dos aspectos menos glamorosos da vida não teria muito interesse ou sentido - afinal, celebridades não falam que dormiram mal a noite anterior, que pegaram o metrô lotado ou que estão com dor nas costas. No entanto, trabalhar apenas esse conjunto de dados não seria suficiente. Assim, procurei diferenciar a pesquisa que estava realizando da pesquisa jornalística, que possui uma abordagem e um tempo distinto - das reportagens que os sapeurs participaram e que pude acompanhar, a mais longa foi para um canal de TV congolês, para a qual a equipe de filmagem passou uma semana com eles, e a mais curta foi por telefone para uma emissora de rádio, que durou cerca de duas horas. O convívio mais cotidiano e por um tempo mais prolongado fez com que as pessoas naturalizassem a minha presença ali e foi essencial para que eu conseguisse ultrapassar essa primeira barreira de um discurso produzido para as mídias.

Além do tempo, o próprio desejo dos sapeurs em serem reconhecidos também me auxiliou a aprofundar o campo. Como afirmei anteriormente, os sapeurs 
recebem muito bem qualquer pessoa que se proponha a escrever, filmar ou fotografá-los, pois veem isso como uma forma de publicidade, o que é sempre bemvindo. Houve mesmo sapeurs que chegaram a me ligar para marcar encontros comigo e me convidar para eventos nos quais iriam se apresentar. Era uma troca de dons: eles me ofereciam seu tempo e aceitavam a minha presença ali e, em contrapartida, eu os oferecia um espaço a mais no qual eles seriam retratados; ainda que esse espaço não contasse, nem de longe, com a mesma relevância que é concedida aos meios de comunicação, congoleses e franceses, mais tradicionais, tais como televisão, revistas e rádios.

Consequentemente, as pessoas que tinham maior interesse em participar da pesquisa eram os sapeurs que estavam regulares na França, por não terem nenhum receio em se mostrarem. Os sapeurs que estão irregulares acabam vivendo uma situação difícil de conciliar. Por um lado, enquanto performers e pessoas que almejam o estrelato, eles têm que se mostrar e se apresentar em público, já que a SAPE é, também, uma performance pública. Mas, por outro lado, enquanto imigrantes irregulares, são mais cuidadosos ao se exibirem e acabam priorizando realizar esta performance em espaços mais exclusivos à comunidade congolesa. Como os irregulares costumam evitar os meios de comunicação tradicionais, preferindo as redes sociais e mídias digitais, isso gera um desequilíbrio entre regulares e irregulares quanto aos recursos que podem lançar mão para se tornarem reconhecidos.

Vale lembrar que, para a sociedade francesa, eles não são sapeurs, mas imigrantes africanos como todos os outros; uma vez que a categoria de sapeur nem sequer é inteligível para a maioria dos franceses. Se, como visto, a sociedade de acolhida tende a ignorar a vida do indivíduo antes de cruzar as fronteiras, no caso da SAPE isso é ainda mais marcado, pois significa um anonimato para o país de residência. Era importante, então, que eu demonstrasse estar ciente deste papel de celebridades que eles ocupam para a comunidade de origem congolesa.

Ser brasileira me colocava em uma posição peculiar, uma vez que, se a pesquisa não competia com as mídias que eles costumam utilizar, por outro lado minha nacionalidade expandia as fronteiras da SAPE para além dos locais que ela tradicionalmente alcança. Assim, o sapeur Bachelor, ao me apresentar a seus amigos, não deixava de acrescentar: "e ela veio do Brasil para falar comigo e escrever sobre mim. Você sabe onde fica o Brasil, não sabe? Então, veja que até lá eu sou conhecido". Isto fez com que eles tivessem interesse em me conceder seu tempo e boa vontade ao me permitir participar de seus espaços de sociabilidade e em abrir suas casas e guarda-roupas para mim, pois essa era uma contrapartida que eu poderia lhes oferecer.

Afirmei anteriormente que acompanhei a gravação de um programa para um canal de TV congolês sobre os sapeurs que vivem em Paris. Este foi um evento marcante para que eles me abrissem as portas de diversos espaços que costumam frequentar, ainda que não tenha sido isento de contratempos. Como visto, os sapeurs utilizam os meios de comunicação para aumentarem seu prestígio. E, durante a gravação do programa, utilizaram também da minha presença enquanto pesquisadora brasileira para o mesmo fim. Eu estava interessada em saber mais sobre eles e vinha de um lugar distante e exótico, o que também poderia significar que mesmos nos confins mais distantes e exóticos do globo as pessoas se interessavam por eles. Assim, eles quiseram que eu participasse de suas entrevistas, afirmando para a televisão congolesa o quanto eram famosos até na América Latina. O sapeur Dada Pourret quis que eu contasse para a câmera como foi que eu soube dele, ao que eu respondi que havia sido por meio de um filme em uma plataforma 
digital. Dada, então, afirma confiante para a câmera: "como vocês podem confirmar, meus filmes são um sucesso até no Brasil”. Eu era, portanto, a prova viva deste estrelato tupiniquim. Percebendo que isso me dotava de uma funcionalidade em campo, não hesitei em reforçar, nesta e em muitas outras ocasiões, o quanto eles eram conhecidos na América do Sul, o que os deixava muito satisfeitos.

Isso fez com que eles passassem a me convidar a muitos de seus espaços de sociabilidade e me apresentassem a cada vez mais pessoas, para quem eu sempre afirmava o quanto o sapeur que me havia apresentado ou convidado era famoso no continente americano. Isso me permitiu observar como eles interagem entre si e pude privilegiar esta proposta de uma etnografia "de perto e de dentro". Ironicamente, foi justamente a relação dos sapeurs com as mídias - no caso, a entrevista para a televisão - que fez com que eles me permitissem ultrapassar a barreira, presente no início do campo, desta forma já ensaiada de se apresentarem para os meios de comunicação e finalmente acessar o cotidiano deles. Só retornei às entrevistas mais ao final do campo. Em muitos casos, fiz mais de uma entrevista com o mesmo sapeur, porém com objetivos diferentes: a primeira entrevista, na qual o entrevistado buscava replicar este modelo mais "jornalístico", e uma segunda entrevista após este período de convivência mais prolongado, que fluía de maneira bem diferente da primeira.

No entanto, esta reportagem de TV também provocou alguns dramas em campo que tive que administrar. Não havia sido previamente informada de que haveria a tal reportagem. Simplesmente, os sapeurs Bachelor e Dada Pourret me disseram que não deixasse de ir à loja Connivences no dia seguinte. Segui a recomendação e, quando cheguei lá, me deparei com a equipe de filmagem. Não sabia que haveria outros dias de gravação e que outros sapeurs também seriam entrevistados, então contei do sucesso brasileiro apenas daqueles que estavam ali presentes. Isso acabou gerando ciúmes no sapeur Mukasha, que seria entrevistado no dia seguinte. Felizmente, ainda havia toda uma semana de filmagens pela frente, o que me deu oportunidade de reverter a situação antes que a equipe voltasse para Kinshasa. Aproveitei o tempo que restava para falar sobre a fama brasileira de Mukasha e afirmar para a câmera como todos os sapeur que participaram da reportagem eram muito famosos no Brasil. Assim, consegui contornar a situação mas, sobretudo, aprendi a ficar mais atenta a que os sapeurs, como é de se esperar se tratando que se pensam como celebridades, são pessoas que possuem egos importantes e que eu deveria prestar mais atenção em como administrar esta questão ao longo do campo.

Por vezes, participar da pesquisa ou não, ser entrevistado ou não, poderia mesmo ser lido como uma forma de reconhecimento do sapeur. Assim, sabia que se entrevistasse um determinado sapeur mais de uma vez, igualmente teria que entrevistar outro pela segunda vez. Da mesma forma, havia alguns sapeurs que, por sua centralidade no meio da SAPE, não poderiam deixar de ser entrevistados, e não só por meu interesse como pesquisadora em ouvir o que eles tinham a dizer, mas pela própria posição que ocupavam no campo.

Sapeurs são pessoas vaidosas, tanto no sentido de se dedicarem ao cuidado da própria aparência quanto no sentido de desenvolverem uma elevada autoestima associada à valorização do conjunto de práticas e valores que os identificam como membros da sapelogie. Mas, além disso, eles são também pessoas que estão habituadas a se sentirem à vontade frente as câmeras. É um conhecimento complexo, pois demanda que uma série de disposições sejam incorporadas por meio de uma prática prolongada. 
Daí a maneira confiante com que o sapeur Norbat de Paris participou de um reality show ${ }^{7}$ sobre moda na TV aberta francesa, sendo o único candidato estrangeiro do programa. Norbat não chegou ao programa de maneira humilde, e sim afirmando que os demais candidatos, todos eles franceses e brancos, alguns dos quais não hesitaram em debochar de Norbat, iriam "tremer e fazer xixi nas calças" ao conhecerem toda a elegância de sua "potência norbática" ("puissance norbatique"), que é como ele gosta de chamar seu carisma, e que iria desclassificá-los da competição. Norbat mostrou, orgulhoso, seu guarda-roupa para a câmera e apareceu vestido como sapeur durante toda a semana que durou o programa. Habituado a dialogar com os meios de comunicação, a desfilar e a participar de competições de elegância, Norbat de Paris se mostrou muito à vontade no reality show e levou enorme vantagem frente aos demais concorrentes, que eram todos, o que venho chamando de "pessoas comuns", não-celebridades. Norbat estava consciente desta vantagem e chegou ao programa de TV para ganhar a competição - o que, não é de surpreender, de fato aconteceu.

Assim, entendo que isso gera um tipo de subjetividade diferente em relação a outros grupos que não contam com este reconhecimento em seu país de origem. Viver e trabalhar na França tendo fotos suas publicadas em revistas ou sua imagem transmitida em canais de TV de seu país é diferente de viver e trabalhar na França sendo anônimo tanto em Paris quanto no país natal. Este reconhecimento que os sapeurs possuem para o público congolês confere a eles uma posição valorizada dentro do seu próprio grupo social, que não apenas dá a eles o sentimento de pertencimento à comunidade de origem como valoriza a própria experiência do fluxo transnacional. Por mais que enfrentem uma série de dificuldades em seu cotidiano como imigrantes africanos na França, o discurso é de afirmação e orgulho. O desejo de visibilidade fala da busca de um ganho que não é exclusivamente material, mas simbólico e mesmo os que ainda estão começando a comprar suas roupas de grife têm a expectativa de um dia serem famosos e reconhecidos nos Congos.

Isso coloca a SAPE como, muito mais do que uma busca por roupas grifadas, uma reflexão sobre as relações entre Congo e França, assim como sobre o próprio fluxo entre estes dois países que os sapeurs, simultaneamente, habitam. É, também, um movimento de afirmação da africanidade e da negritude, que busca englobar a alteridade como forma de se afirmar. As roupas da SAPE são uma antropofagia das roupas francesas e uma forma de refletir, através das atividades performáticas, da relação com os objetos e de múltiplos meios de expressão, sobre a pós-colonialidade e o cotidiano da população congolesa ou de origem congolesa em Paris. E, neste contexto, ser brasileira e mestiça me ajudou na entrada em campo.

Ser brasileira era contar com um imaginário longínquo, porém simpático. Além do que, cheguei a França no período em que estava ocorrendo a Copa do Mundo no Brasil, o que colocava o país em evidência, assim como sua relação com o esporte, que era constantemente acionada (GUEDES, 1998). Minha origem era tida como exótica e, por isso mesmo, exterior às relações que eles mantêm com os franceses. E, assim como eles, eu também era uma estrangeira na França, ainda que chegada ao país por meio de um fluxo muito distinto do deles, e era vinda de um país periférico e mestiça.

Isso se apresentou de forma mais marcante no período que sucedeu o atentado à revista Charlie Hebdo, que ocorreu na metade do trabalho de campo. Foi 
algo que modificou toda a atmosfera e rotina da cidade e, consequentemente, trouxe novas questões para o campo. Todos falavam sobre o que havia se passado e o que poderia ocorrer dali para frente mas, em Château Rouge e Goutte D' Or se considerava que nem tudo deveria ser dito a qualquer pessoa - pois, dependendo do interlocutor, se afirmar como não "sendo Charlie" ${ }^{8}$ poderia ser muito mal compreendido. Assim, várias vezes, ouvia sapeurs e imigrantes não-sapeurs, ao discutirem o ocorrido, afirmarem que "tem certas coisas que não se deve falar aos franceses, sob o risco de ser mal interpretado". Ser brasileira, então, me permitiu ouvir comentários sobre a presente situação que eu não teria tido acesso se fosse francesa e que me auxiliaram a compreender melhor a respeito da interação, nem sempre tranquila e quase nunca horizontal, dos sapeurs, como imigrantes congoleses, com a sociedade francesa.

Busquei, a partir destas duas etnografias, refletir sobre a entrada e a construção do campo em um contexto de fluxo transnacional, observando as peculiaridades que cada grupo estudado traz consigo e olhando também seus pontos em comum, que a própria situação de trânsito internacional faz com que compartilhem. Sendo assim, o artigo busca contribuir a compreender melhor a posição que o Brasil ocupa nestes trânsitos, enquanto país que segue periférico, mas que experimentou um período em que expandiu sua presença no âmbito internacional, tanto diplomático quanto acadêmico. Esta presença se reflete no fluxo em direção ao país, atraindo jovens pesquisadores estrangeiros a realizarem sua formação aqui, a produzirem conhecimento na universidade brasileira e em diálogo com a academia brasileira e, em alguns casos, a optarem por viver aqui também. Da mesma forma, aquele dado contexto também impulsionou o fluxo no sentido contrário, do Brasil em direção a outros países, viabilizando que mais brasileiros realizassem pesquisa no exterior e ampliando os limites da antropologia brasileira, mas também trouxe questionamentos a respeito das implicações de ser um pesquisador brasileiro fora das fronteiras nacionais.

Recebido em 30 de outubro de 2019.

Aceito em 6 de janeiro de 2020. 


\section{Referências}

APPIAH, Kwame Anthony. Na casa de meu pai. Rio de Janeiro: Contraponto, 1997.

BALANDIER, Georges. Sociologia das Brazzavilles negras. Luanda: Ed. Pedagos \& Ed. Mulemba da Faculdade de Ciências Sociais da Universidade Agostinho Neto, 2013.

BEHAR, Ruth. Rage and redemption: reading the lie story of a mexican marketing woman. Feminist Studies, 16 (2): 223-58, 1990.

BOURDIEU, Pierre. "Compreender". In: BOURDIEU, Pierre (org.) A miséria do mundo. Petrópolis: Vozes, 1997. pp. 693-73.

BOURDIEU, Pierre. "Alta costura e alta cultura". In: BOURDIEU, Pierre. Questões de sociologia. Rio de Janeiro: Marco Zero, 1983. pp. 154-161.

CESARINO, Letícia. Antropologia multissituada e a questão da escala: reflexões com base no estudo da cooperação Sul-Sul brasileira. Horizontes Antropológicos, 20 (41): 19-50, 2014.

CESARINO, Letícia. Anthropology of development and the challenge of SouthSouth cooperation. Vibrant, 9 (1): 507-537, 2012.

ELLERY, Daniele. Identidades em trânsito - África "na pasajen": identidades e nacionalidades guineenses e cabo-verdianas. Campinas: Arte Escrita Ed., 2009.

GUEDES, Simoni Lahud. O Brasil no campo do futebol: estudos antropológicos sobre os significados do futebol brasileiro. Rio de Janeiro: EDUFF, 1998.

HAGE, Ghassan. A not so multi-sited ethnography of a not so imagined community. Anthropological Theory. 5 (4): 463-475, 2005.

HIRSCH, Olívia Nogueira. "Hoje me sinto africana": processos de (re) construção de identidades em um grupo de estudantes cabo-verdianos no Rio de Janeiro. Dissertação de mestrado, Ciências sociais, PUC-RIO, 2007.

KALY, Alain. O ser preto africano no "paraíso terrestre" brasileiro: um sociólogo senegalês no Brasil. Lusotopie, Lisboa: 105-121, 2001.

LECHINI, Gladys. O Brasil na África ou a África no Brasil? A construção da política africana pelo Itamaraty. Nueva Sociedad, Especial Brasil, Outubro: 55-71, 2008.

MARTIN, Phyllis M. Contesting Clothes in Colonial Brazzaville. The Journal of African History, 35 (3): 401-426, 1994.

MBEMBE, Achille. On the postcolony. Berkeley: University of California Press, 2001.

MEDIAVILLA, Héctor. S.A.P.E. Paris: Editions Intervalles, 2013.

MORAIS, Sara Santos. Múltiplos regressos a um mundo cosmopolita: moçambicanos formados em universidades brasileiras e a construção de um sistema de prestígio em Maputo. Dissertação de mestrado, Antropologia Social, UNB, 2012.

MUNGOI, Dulce Maria Domingos Chale João. "O mito atlântico": relatando experiências singulares de mobilidade dos estudantes africanos em Porto Alegre 
no jogo de construção e reconstrução de suas identidades étnicas. Dissertação de mestrado, Antropologia Social, PPGAS/UFRGS, 2006.

MUNANGA, Kabengele. Rediscutindo a Mestiçagem no Brasil: Identidade Nacional versus Identidade Negra. Belo Horizonte: Autêntica, 2004.

PEIRANO, Mariza. A favor da etnografia. Rio de Janeiro: Relume Dumará, 1995. PIRES, Rogério Brittes. Futuros que seguem: Multiplicidade espaço temporal businenge no Suriname pós-colonial. Ilha, 19 (2): 143-174, 2017.

SAYAD, Abdelmalek. A imigração: ou os paradoxos da alteridade. São Paulo: EDUSP, 1998.

SARAIVA, Flávio Sombra. A busca de um novo paradigma: política exterior, comércio externo e federalismo no Brasil. Revista Brasileira de Política Internacional, 47 (02): 131-162, 2004.

SUBUHANA, Carlos. Estudar no Brasil: imigração temporária de estudantes moçambicanos no Rio de Janeiro. Tese de doutorado, Serviço Social, UFRJ, 2005.

VELHO, Gilberto. Projeto e metamorfose: antropologia das sociedades complexas. Rio de Janeiro: Jorge Zahar, 1994.

VISENTINI, Paulo Fagundes. O Brasil e a história das relações internacionais. Revista Esboços, 21 (32): 18-40, 2015.

VIVEIRO DE CASTRO, Eduardo. O campo na selva, visto da praia. Estudos Históricos, 5 (10): 170-190, 1992. 


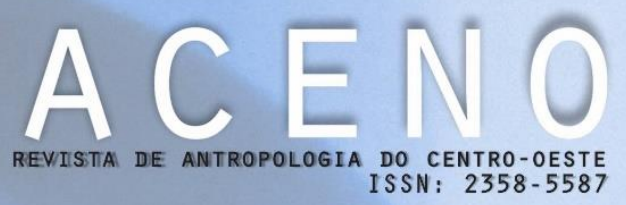

A Aceno - Revista de Antropologia do Centro-Oeste recebe o ano inteiro, em

\section{FLUXO

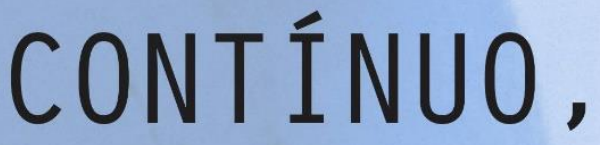

artigos livres, resenhas, ensaios fotográficos, dossiês (propostas).

Interessados na submissão de trabalhos e também em atuar como

\section{pareceristas}

podem realizar seus cadastros em

https://periodicoscientificos.ufmt.br/ojs/index.php/aceno 